\title{
EXECUÇÃO DE PROJETOS DE EXTENSÃO EM PERÍODO DE PANDEMIA: AUTOAVALIAÇÃO E ESTRATÉGIAS
}

\section{EXECUTION OF EXTENSION PROJECTS IN A PANDEMIC PERIOD: SELF- ASSESSMENT AND STRATEGIES}

\section{EJECUCIÓN DE PROYECTOS DE EXTENSIÓN EN PERÍODO PANDÉMICO: AUTOEVALUACIÓN Y ESTRATEGIAS}

Bárbara Guedes Aguiar ${ }^{1}$ https://orcid.org/0000-0002-8368-2099

Luiza Loren Vieira Tavares ${ }^{2}$ https://orcid.org/0000-0003-1794-8255

Alesson Pires Maciel Guirra ${ }^{3}$ https://orcid.org/0000-0003-4201-3574

Flaviana Tavares Vieira Teixeira ${ }^{4}$ https://orcid.org/0000-0003-3797-1778

\footnotetext{
${ }^{1}$ Graduanda em Bacharelado em Ciência e Tecnologia - Universidade Federal dos Vales do Jequitinhonha e Mucuri - Diamantina, Brasil. E-mail: babguiar@gmail.com

${ }^{2}$ Graduanda em Bacharelado em Ciência e Tecnologia - Universidade Federal dos Vales do Jequitinhonha e Mucuri - Diamantina, Brasil. E-mail: luizal.vieirat@gmail.com

3 Técnico Administrativo - Universidade Federal dos Vales do Jequitinhonha e Mucuri - Instituto de Ciência e Tecnologia, Diamantina, Brasil. E-mail: engeoguirra@gmail.com

${ }^{4}$ Docente de Engenharia Química, Tutora do Programa de Educação Tutorial Estratégias para Diminuir a Retenção e Evasão Universidade Federal dos Vales do Jequitinhonha e Mucuri - Instituto de Ciência e Tecnologia, Diamantina, Brasil. E-mail: flaviana.tavares@ict.ufvjm.edu.br
}

\section{RESUMO}

Diante dos desafios refletidos na implantação, manutenção e sustentabilidade dos projetos de extensão ofertados pelo Programa de Educação Tutorial PET-Estratégias para Diminuir a Retenção e Evasão na Universidade Federal dos Vales do Jequitinhonha e Mucuri, torna-se relevante demonstrar, na percepção dos Petianos e Coordenadores, quais são as estratégias adotadas para viabilizar a execução dessas atividades. A coleta de dados foi realizada por meio da aplicação de um questionário online utilizando a plataforma Google Forms. Para análise dos dados qualiquantitativos utilizou-se cálculos percentuais a partir da elaboração de tabelas e gráficos. A pesquisa possibilitou o registro de opiniões sobre as fragilidades em relação ao desenvolvimento remoto dos projetos. Os resultados demonstram que não foi possível prosseguir com a maioria dos projetos de extensão e que o advento da pandemia se tornou um fator limitante para execução das atividades, além da ausência de recursos tecnológicos e dificuldades relatadas pelos voluntários no acesso à internet. Ainda assim, o PET se empenhou em desenvolver estratégias para driblar tais limitações, através da produção de vídeos disponibilizados nas mídias sociais, assim como a inserção dos estudantes em congressos brasileiros nacionais, estimulando a troca de experiências, a disseminação do conhecimento e a divulgação científica.

Palavras-chave: Atividades Extracurriculares. Programa de Educação Tutorial. COVID-19. 


\begin{abstract}
Given the challenges reflected in the implementation, maintenance and sustainability of the extension projects offered by the Tutorial Education Program PET-Strategies to Reduce Retention and Evasion at the Federal University of the Valleys of Jequitinhonha and Mucuri, it is relevant to demonstrate, in the perception of Petianos and Coordinators, what are the strategies adopted to enable the execution of these activities. Data collection was carried out through the application of an online questionnaire using the Google Forms platform. For the analysis of qualitative and quantitative data, descriptive statistics were used based on the preparation of tables and graphs. The research made it possible to register opinions on the weaknesses in relation to the remote development of the projects. The results demonstrate that it was not possible to proceed with most extension projects and that the advent of the pandemic became a limiting factor for the execution of activities, in addition to the lack of technological resources and difficulties reported by volunteers in accessing the internet. Even so, PET endeavored to develop strategies to circumvent such limitations, through the production of videos made available on social media, as well as the insertion of students in Brazilian national congresses, stimulating the exchange of experiences, the dissemination of knowledge and scientific dissemination.
\end{abstract}

Keywords: Extracurricular Activities, Tutorial Education Program, COVID-19.

\title{
RESUMEN
}

Dados los desafíos reflejados en la implementación, mantenimiento y sostenibilidad de los proyectos de extensión que ofrece el Programa de Educación Tutorial PET-Estrategias para Reducir la Retención y Evasión en la Universidad Federal de los Valles de Jequitinhonha y Mucuri, es relevante demostrar, en la percepción de Petianos y Coordinadores, cuáles son las estrategias adoptadas para posibilitar la ejecución de estas actividades. La recolección de datos se llevó a cabo mediante la aplicación de un cuestionario en línea utilizando la plataforma Google Forms. Para el análisis de los datos cualitativos y cuantitativos se utilizó estadística descriptiva basada en la elaboración de tablas y gráficos. La investigación permitió registrar opiniones sobre las debilidades en relación al desarrollo remoto de los proyectos. Los resultados demuestran que no fue posible avanzar con la mayoría de los proyectos de extensión y que el advenimiento de la pandemia se convirtió en un factor limitante para la ejecución de las actividades, además de la falta de recursos tecnológicos y las dificultades reportadas por los voluntarios para acceder a internet. Aun así, PET se esforzó por desarrollar estrategias para sortear tales limitaciones, a través de la producción de videos disponibles en las redes sociales, así como la inserción de estudiantes en congresos nacionales brasileños, estimulando el intercambio de experiencias, la difusión del conocimiento y la divulgación científica.

Palabras clave: Actividades extracurriculares, Programa de educación tutorial, COVID-19.

\section{INTRODUÇÃO}

O Programa de Educação Tutorial (PET) é formado por grupos disseminados em todo o território brasileiro em diversas instituições de ensino, sendo elas públicas ou privadas, geralmente é constituído por no máximo 12 estudantes bolsistas e 06 voluntários (DEARO, 2017). Este grupo é constituído por estudantes que estão ingressos em algum curso de graduação para desenvolver ações de ensino, pesquisa e extensão sob a orientação de um professor tutor. O tutor é responsável em possibilitar a ampliação das experiências na 
formação acadêmica e cidadã dos Petianos. Desta forma, o PET foi criado tendo o objetivo de contribuir com experiências que elevem a formação acadêmica dos alunos de graduação em nível de excelência, otimizando o processo de ensino-aprendizagem e promovendo valores que complementam a carreira acadêmica e profissional de seus alunos (PET, 2011).

O trabalho institucional do PET proporciona um trabalho tutorial de aprendizagem, buscando criar condições para que os estudantes tenham a oportunidade de realizarem atividades extracurriculares. Assim o PET ajuda na qualidade da graduação proporcionando melhores profissionais (CARVALHO, 2018), ao permitir que se tenha um compartilhamento e ampliação dos saberes, tanto dos professores tutores, quanto dos bolsistas e dos demais voluntários envolvidos nos projetos (DEARO, 2017).

Em 1979, a Coordenação de Aperfeiçoamento Pessoal de Nível Superior (CAPES) criou o Programa Especial de Treinamento com o objetivo de aprimorar o ensino superior no Brasil. Em 1999, o programa foi transferido para a Secretaria de Educação Superior do Ministério da Educação (SESU/MEC) e em 2004, passou a ser denominado Programa de Educação Tutorial (DEARO, 2017). Para entrar no grupo do PET como membro bolsista, geralmente ocorre uma seleção baseada em testes e no currículo acadêmico, orientados por um tutor, para desenvolverem atividades extracurriculares norteadas pelo princípio da indissociabilidade entre ensino, pesquisa e extensão (FEITOSA, 2019).

Na Universidade Federal dos Vales do Jequitinhonha e Mucuri (UFVJM), o Programa de Educação Tutorial, PET-Estratégias para Diminuir a Retenção e a Evasão na UFVJM foi criado em 2010, com objetivo de reduzir a taxa de retenção e evasão nos cursos de graduação. Algumas das estratégias adotadas pelo grupo, é propiciar oportunidades para estudantes atuarem em projetos de ensino, pesquisa e extensão, propiciando-lhes condição de ampliação de seu campo de visão e favorecendo sua integração ao ambiente acadêmico (PET, 2020). Desta forma, realizou-se a chamada pública para a seleção de interessados em participar voluntariamente de projetos de extensão para o primeiro semestre de 2020/1.

O público alvo do PET Estratégias são estudantes universitários que encontram-se em estado de vulnerabilidade socioeconômica, com coeficiente de rendimento acadêmico (CRA) menores que a média para ser aprovado em disciplinas $(60,0)$, ou que possuam uma ou mais reprovações em disciplinas da graduação. $\mathrm{O}$ estudante sendo selecionado e tendo escolhido o projeto de extensão que fará parte, tem ciência pelo edital que, ao fazer parte da equipe ele se compromete como responsável a realizar o plano de trabalho descrito, compreendendo capacitação e desenvolvimento do projeto, comprometendo-se a dedicar a quatro horas semanais durante três meses (PET, 2020). 
O recente cenário de expansão epidêmica em nível global, provocada pela COVID-19, trouxe à tona uma avassaladora crise humanitária que vai além da questão sanitária propriamente dita, marcada pelo crescente número de vítimas em todo o mundo, também afeta a educação, em virtude das medidas de isolamento social indicadas como forma de conter a proliferação viral (SILVA, 2020).

Com a COVID-19 as instituições públicas e privadas realizaram as orientações governamentais em realizar aula de forma remota, virtual, ainda sem uma previsão de retorno as aulas presenciais. As atividades online apesar das dificuldades, foram necessárias para minimizar os prejuízos da ausência das aulas presenciais por um longo período (CORDEIRO, 2020). Assim, foi necessário que todos se adaptassem academicamente, assim o estudante teve que encarar novas exigências tendo que ter maior autonomia e desempenho o processo de adaptação é complexo envolvendo diversos fatores relacionados ao desenvolvimento institucional, vivências e rendimento acadêmico, entre outras condutas que necessitam ser realizadas (IGUE et al., 2008). Nesse momento alguns sentimentos como medo, insegurança das mudanças e a incerteza, a autoeficácia e adaptação acadêmica podem ter tido grandes impactos (BRAGIATTO, 2020).

Uma das maiores dificuldades do período emergencial foi que muitas instituições de ensino público relataram que uma parte dos estudantes não possui acesso à internet ou a computadores, o que impacta diretamente no ensino de qualidade, podendo assim aumentar os índices de evasão escolar. Com isso, houve a necessidade das instituições públicas criarem mecanismos para poder incluir os estudantes sem esse acesso, mesmo que isso seja um problema eminente desde antes da pandemia (GARCIA et al., 2020). O Instituto Brasileiro de Geografia e Estatística (IBGE) (2018), realizou um levantamento em que cerca de 13\% não têm acesso a computadores e $10 \%$ das famílias brasileiras não possui acesso à internet.

A falta dos recursos digitais apresenta um risco para a educação, pois há a exclusão de estudantes que não são compatíveis com a modalidade de ensino remoto/virtual, por não possuírem internet e/ou computadores (OCDE, 2020). Mesmo que ainda não se saiba todos os efeitos do ensino remoto, algumas consequências já podem ser notadas sendo: queda no êxito escolar, aumento da evasão no ensino superior, queda no rendimento acadêmico e a sobrecarga dos docentes, principalmente por ter que lidar com as novas tecnologias (GUSSO et al., 2020). Dado esse contexto emergencial, novas estratégias precisaram ser elaboradas, para que o PET conseguisse seguir com o desenvolvimento dos projetos.

Nesse contexto de pandemia, bem como dos riscos sociais a ele vinculados, a extensão universitária surge, então, como um canal desafiador, entretanto, possa ser visto como um 
cenário aberto a novas possibilidades, podendo fomentar debates acerca do PET e da inserção e disseminação dos conhecimentos em ações de ensino, pesquisa e extensão. Diante disso, o objetivo é realizar uma pesquisa de autoavaliação dos projetos executados pelo Programa de Educação Tutorial (PET) no semestre 2020/1 e demonstrar quais são as estratégias adotadas para viabilizar a execução das atividades no período de isolamento social forçado pela pandemia da COVID-19.

\section{MATERIAIS E MÉTODOS}

Tendo em vista a complexidade dos fenômenos sociais, tornou-se necessário adotar métodos de pesquisa que considerassem tal dificuldade, uma vez que este estudo retrata, na pesperctiva de Coordenadores e Petianos, o desenvolvimento dos projetos de extensão na pandemia. Sendo assim, optou-se por uma pesquisa de natureza qualiquantitativa. De acordo com Minayo (2002), os tratamentos qualitativos e quantiativos dos resultados podem ser complementares, enriquecendo a análise e as discussões finais. Nesta perspectiva, a pesquisa qualitativa pode ser apoiada pela pesquisa quantitativa e vice-versa, possibilitando uma análise estrutural do fenômeno com métodos quantitativos e uma análise processual mediante métodos qualitativos (SCHNEIDER, 2017).

A pesquisa foi realizada totalmente de forma remota devido ao momento mundial da COVID-19, sendo preciso promover reuniões em ambiente virtual pela plataforma Google Meet para acertar os detalhes necessários, tais como: delimitação do tema, elaboração das perguntas nos formulários, prazos para resposta, entre outras questões pertinentes. Essa fase inicial possibilitou construir embasamento teórico e conceitual sobre o tema, a exploração do material relacionado a atuação do Programa de Educação Tutorial, bem como dos desafios na educação a distância, permitiram uma articulação ao cenário atual da sociedade, viabilizando uma melhor compreensão do fenômeno. E por fim, o estudo sobre as abordagens de pesquisa possibilitou interpretar os instrumentos utilizados e as metodologias empregadas para análise dos dados (SCHNEIDER, 2017).

No Quadro 1 transcreve-se os projetos ofertados pelo PET Estratégias em estudo nesta pesquisa. O programa possui colaboradores docentes dos cursos de agronomia, odontologia, medicina, educação física, nutrição, bacharelado em humanidades, enfermagem, história, geografia, engenharias e bacharelado em ciência e tecnologia. No total foram ofertadas 188 vagas distribuídas em 39 projetos sobre as mais diversas temáticas. No que tange à natureza da pesquisa, evidencia-se a necessidade em analisar e discutir o desenvolvimento dessas ações 
de extensão, com base em elementos provenientes da consolidação e análise dos dados gerados pelos Coordenadores e pelos Petianos que intermediam tais atividades.

Quadro 1: Projetos de extensão ofertados pelo PET Estratégias 2020/1.

\begin{tabular}{|c|c|c|c|}
\hline \multicolumn{4}{|c|}{ Projetos de Extensão para o Primeiro Semester de 2020} \\
\hline $\begin{array}{l}\text { Apoio extraclasse na } \\
\text { utilização de softwares } \\
\text { das Geotecnologias }\end{array}$ & $\begin{array}{r}\text { A Voz das Mulheres } \\
\text { Negras no Âmbito } \\
\text { Acadêmico: a base da } \\
\text { pirâmide patriarcal } \\
\text { rompendo e } \\
\text { desestruturando o sistema } \\
\end{array}$ & $\begin{array}{r}\text { Agronomia e } \\
\text { Doenças de } \\
\text { Plantas }\end{array}$ & $\begin{array}{r}\text { Academia ao Ar } \\
\text { Livre: incentivando } \\
\text { práticas de } \\
\text { exercícios físicos na } \\
\text { universidade }\end{array}$ \\
\hline $\begin{array}{l}\text { Desenvolvimento de } \\
\text { produtos usando } \\
\text { materiais recicláveis. }\end{array}$ & $\begin{array}{r}\text { Ecologia Política dos } \\
\text { recursos naturais e serviços } \\
\text { ecossistêmicos na } \\
\text { comunidade quilombola de } \\
\text { Monte Alegre em } \\
\text { Veredinha-MG (Vale do } \\
\text { Jequitinhonha) }\end{array}$ & $\begin{array}{r}\text { Desenvolvimen } \\
\text { to Tecnológico } \\
\text { de Tapioca } \\
\text { enriquecida } \\
\text { com novos } \\
\text { cereais }\end{array}$ & $\begin{array}{r}\text { Ambiente escolar: } \\
\text { espaço para } \\
\text { promoção da saúde e } \\
\text { da alimentação } \\
\text { saudável }\end{array}$ \\
\hline $\begin{array}{l}\text { Cervejaria Escola- } \\
\text { UFVJM }\end{array}$ & Geografia em Comunidade & Ver Ciência & $\begin{array}{r}\text { Curso de primeiros } \\
\text { socorros }\end{array}$ \\
\hline $\begin{array}{l}\text { Psicologia, cultura e } \\
\text { formação da pessoa: } \\
\text { realização de oficinas } \\
\text { culturais com crianças } \\
\text { abrigadas na Associação } \\
\text { de Amigos da Casa Lar } \\
\text { Diamantina }\end{array}$ & $\begin{array}{r}\text { Interações formiga- } \\
\text { plantapolinizador em } \\
\text { sistemas vegetais afetados } \\
\text { por fogo: Efeitos dos } \\
\text { distintos regimes de fogo } \\
\text { sobre o processo de } \\
\text { polinização e a reprodução } \\
\text { vegetal }\end{array}$ & $\begin{array}{r}\text { Site de } \\
\text { divulgação e } \\
\text { capacitação } \\
\text { acadêmica: } \\
\text { Acadêmicos } \\
\text { dos Vales }\end{array}$ & $\begin{array}{r}\text { Diamantina Radical } \\
\text { e Aventuras - } \\
\text { desenvolvimento da } \\
\text { cultura do skate } \\
\text { street e da escalada } \\
\text { em rocha }\end{array}$ \\
\hline $\begin{array}{l}\text { Criação de um espaço de } \\
\text { ciência e cultura em } \\
\text { Conselheiro Mata }\end{array}$ & $\begin{array}{r}\text { Inventário, Higienização e } \\
\text { Organização de Acervo } \\
\text { Documental do Periódico } \\
\text { Estrela Polar, Diamantina, } \\
\text { MG }(1903-2019) .\end{array}$ & Dê uma canja & $\begin{array}{r}\text { Garimpando o } \\
\text { cotidiano: cultura, } \\
\text { experiência e } \\
\text { promoção da saúde } \\
\text { mental } \\
\end{array}$ \\
\hline $\begin{array}{l}\text { Geomicrobiologia das } \\
\text { Cavernas de Quartizito na } \\
\text { Região de Diamantina }\end{array}$ & $\begin{array}{r}\text { Laproce: Laboratório de } \\
\text { Produção de Conteúdo } \\
\text { Educacionais }\end{array}$ & $\begin{array}{r}\text { Implantação do } \\
\text { Laticínio } \\
\text { Escola da } \\
\text { UFVJM } \\
\end{array}$ & $\begin{array}{r}\text { Levantamento do } \\
\text { perfil do estudante } \\
\text { de graduação da } \\
\text { odontologia } \\
\end{array}$ \\
\hline $\begin{array}{l}\text { Desastres naturais em } \\
\text { Diamantina }\end{array}$ & $\begin{array}{r}\text { NUPEDE - Núcleo de } \\
\text { Pesquisa, Ensino, Extensão } \\
\text { e Divulgação sobre } \\
\text { Escravidão } \\
\end{array}$ & $\begin{array}{r}\text { Lapidação de } \\
\text { Vida } \\
\text { Independente }\end{array}$ & $\begin{array}{r}\text { PETricô - } \\
\text { Aquecendo com arte }\end{array}$ \\
\hline $\begin{array}{l}\text { Elaboração de um app } \\
\text { para agendamento de } \\
\text { reuniões }\end{array}$ & $\begin{array}{r}\text { Oficinas sobre a História de } \\
\text { Diamantina }\end{array}$ & $\begin{array}{r}\text { Química para } \\
\text { Crianças }\end{array}$ & Ser Engenheiro \\
\hline $\begin{array}{l}\text { Exposição "A PréHistória } \\
\text { de Coração de Jesus" }\end{array}$ & $\begin{array}{r}\text { Contribuição para } \\
\text { elaboração de Maquetes }\end{array}$ & $\begin{array}{r}\text { PET EQ na } \\
\text { rede }\end{array}$ & $\begin{array}{r}\text { Birutas em Riacho } \\
\text { dos Ventos }\end{array}$ \\
\hline $\begin{array}{l}\text { Mapeando Riscos de } \\
\text { Acidentes do Trabalho }\end{array}$ & $\begin{array}{l}\text { Rede de proteção a mulher: } \\
\text { rompendo com a violência, } \\
\text { o silencio e a invisibilidade }\end{array}$ & $\begin{array}{r}\text { Horta na } \\
\text { FUMBEM: } \\
\text { cultivando } \\
\text { cidadãos }\end{array}$ & \\
\hline
\end{tabular}

Fonte: Portal da UFVJM, 2020.

Inicia-se a pesquisa pelo fase qualitativa de investigação, a fim de coletar informações visando a intepretação da complexidade dos aspectos. Desta forma, optou-se pela elaboração de questionários semiestruturados direcionadas de forma indenpendente aos grupos distintos, 
Petianos e Coordenadores. A criação dos questionários se deu pela ferramenta gratuita Google Forms. As perguntas eram relacionadas a como foi desenvolver o projeto online, se tornou necessário adaptá-lo ou interrompê-lo, se foi possível realizá-lo e concluir todas as etapas do projeto, sua relevância, como a pandemia afetou a realização de atividades, se houveram dificuldades, habilidades desenvolvidas, entre outros. $O$ foco nessas perguntas permite analisar a eficiência na execução dos projetos, originalmente previstos para realização de forma presencial, em um momento anteior ao isolamento social forçado pela pandemia da COVID-19.

Na sequência, vem a fase quantitativa, em que foi necessário mensurar numericamente os significados do que foi estudado. De posse dos dados coletados, em relação a participação dos membros do PET Estratégias, 100\% responderam ao questionário. No que confere aos Coordenadores, $91,66 \%$ responderam ao instrumento definido para a pesquisa, totalizando em 45 o tamanho da amostra. Para ambos os casos, com suporte a estatística descritiva utilizada neste estudo, a amostragem atingiu um nível de confiança de 95\%. A análise e discussão dos dados visaram traduzir em números as informações coletadas, para classificá-las e analisá-las mediante a utilização de gráficos e cálculos percentuais (SCHNEIDER, 2017). Além de identificar novas proposições de adaptações aos projetos, para que estes sejam passíveis de realização à distância.

\section{RESULTADOS E DISCUSSÃO}

Ao analisar as informações coletadas nos questionários, identificou-se a pandemia da COVID-19 afetou de forma parcial 83,3\% dos projetos de extensão ofertados pelo PETEstratégias neste primeiro semestre de 2020. De acordo com os Petianos, 75\% dos projetos se encontram suspensos, $16,7 \%$ ainda estão em execução e somente $8,3 \%$ foram finalizados. $\mathrm{O}$ Gráfico 1 representa a situação atual dos projetos desenvolvidos a distância. 
Gráfico 1: Status dos projetos ofertados no semestre 2020/1

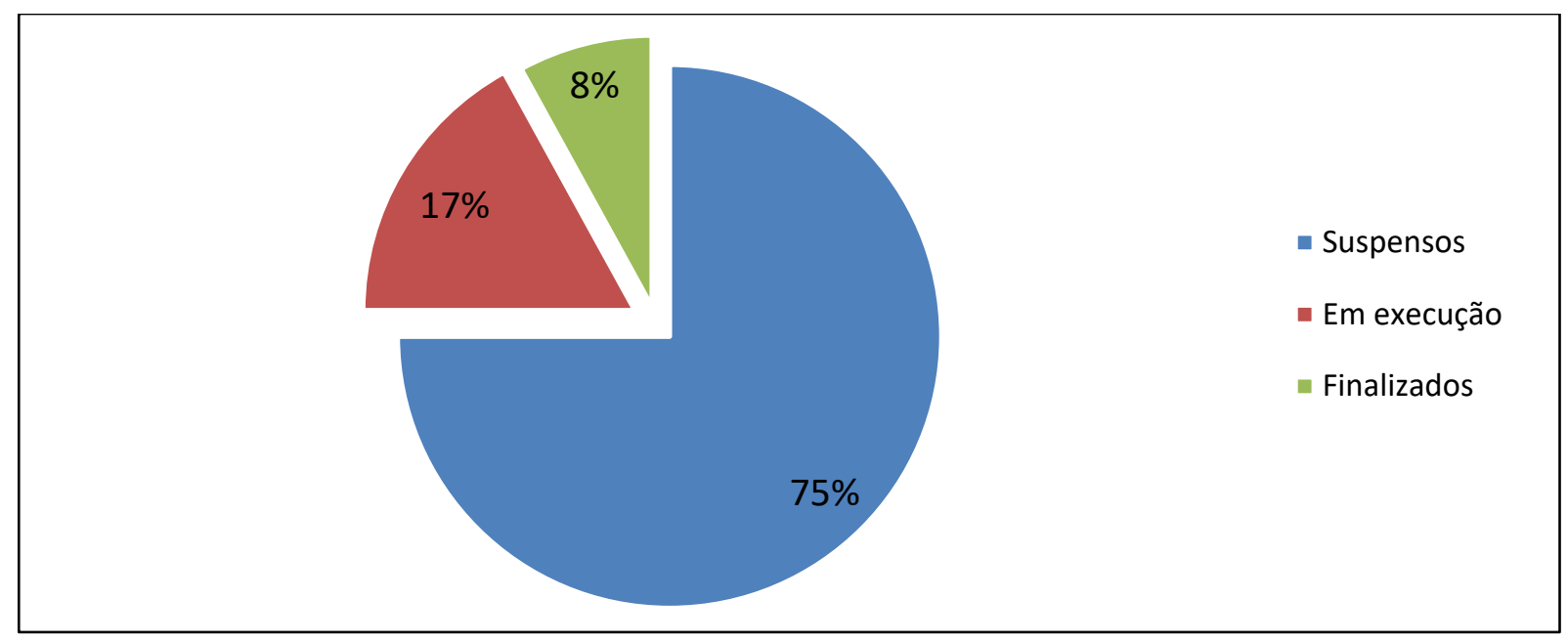

Fonte: Dados da pesquisa (2020)

Diante dos resultados apresentados, nota-se que a pandemia escancara as fragilidades e desigualdades socioeconômicas, estas que refletem diretamente na educação brasileira, uma vez que a evasão dos alunos é um dos fenômenos que mais atinge, preocupa e desafia a modalidade de ensino e aprendizagem a distância (DAUDT, 2013). Neste cenário, o PET convive, no mesmo contexto da ampliação de suas oportunidades e redução dos impactos causados pela pandemia da COVID-19, com a necessidade de adaptações e inovações pedagógicas e tecnológicas, para a manutenção e sustentabilidade dos projetos ofertados.

Quanto à execução dos projetos em home office, 66,7\% dos Petianos relataram dificuldades dos voluntários para realizar as atividades propostas. No que se refere aos recursos e ferramentas tecnológicas, 91,7\% informaram que os alunos não possuíam disponibilidade de acesso à internet. Diante disso, 83,3\% dos Petianos consideram que a ausência de tecnologia foi um fator limitante para execução dos projetos. O Gráfico 2 representa o quanto foi possível desenvolver as atividades. 
Gráfico 2: Apresentação da execução remota dos projetos de extensão

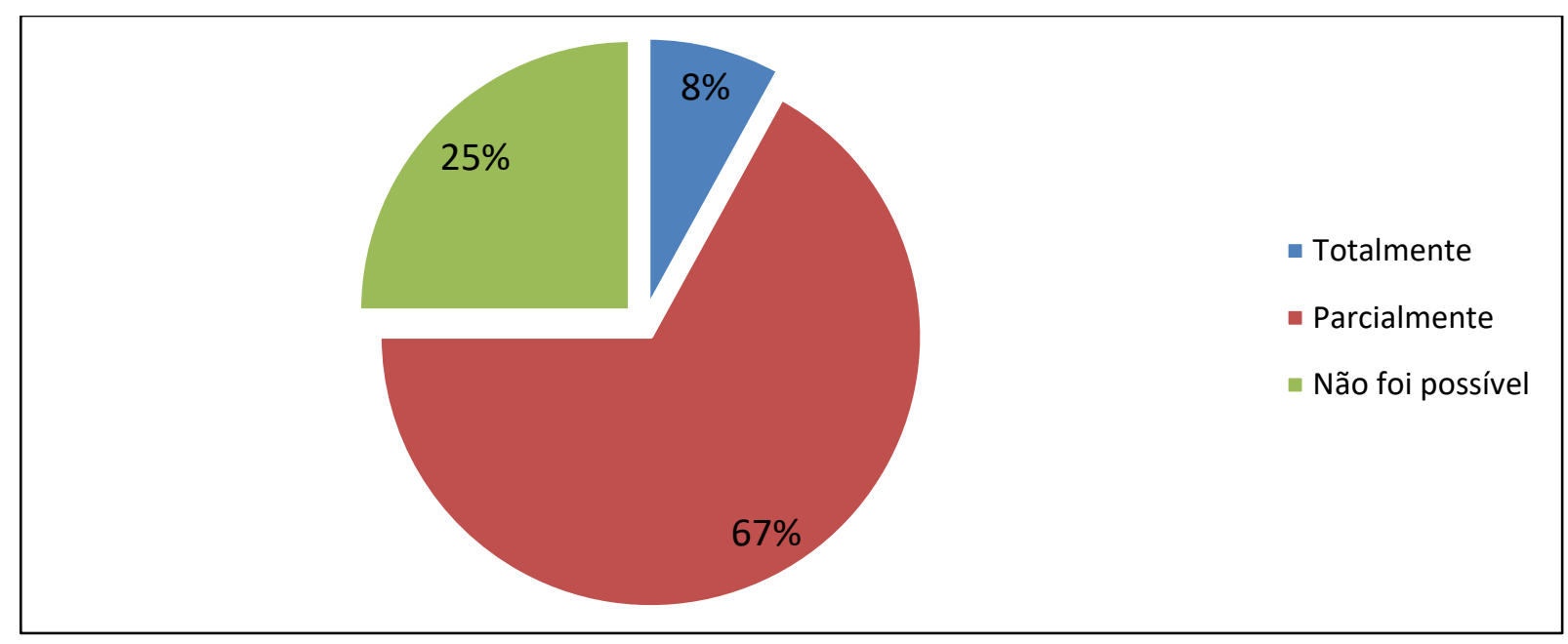

Fonte: Dados da pesquisa (2020)

A diversidade de mídias utilizadas na educação a distância provoca o surgimento de diferentes práticas educacionais. O grupo PET na condição de integrante das redes sociais, buscou adequar-se ao cenário das transformações sociais que as influencia, empenhando-se para encontrar alternativas exequíveis às novas relações com os estudantes voluntários e ao atendimento em suas atuais condições. Assim, foram elaboradas e compartihadas séries em vídeos sobre os projetos de extensão para que os estudantes tenham conteúdos formativos disponibilizados de maneira offline, o que permitiu que $67 \%$ dos projetos de extensão fossem desenvolvidos parcialmente.

No âmbito crítico da execução remota dos projetos de extensão, os Petianos e Coordenadores informaram as principais dificuldades com os voluntários, dentre as quais se destacam a pandemia da COVID-19 representada por 37,25\% de frequência, em seguida a indisponibilidade de internet com 25,49\%, tal como mostra a Tabela 1 . Os resultados da tabela indicam a necessidade de se considerar as disparidades no acesso à internet e as condições dos estudantes antes de introduzir soluções a distância, de forma a avaliar antecipadamente os recursos tecnológicos que já estão disponíveis aos discentes ou que podem ser rapidamente providos. 
Tabela 1: Ocorrências das dificuldades relatadas pelos Petianos e Coordenadores dos projetos.

\begin{tabular}{c|c|c|c}
\hline \multicolumn{3}{c}{ Dificuldades no desenvolvimento remoto dos projetos de extensão } \\
\hline Dificuldades & $\begin{array}{c}\text { Frequência } \\
\text { Absoluta }\end{array}$ & $\begin{array}{c}\text { Frequência } \\
\text { Relativa }\end{array}$ & $\begin{array}{c}\text { Frequência } \\
\text { Relativa } \\
\text { Percentual }\end{array}$ \\
\hline Pandemia & 19 & 0,3725 & $37,25 \%$ \\
\hline Comunicação & 5 & 0,0980 & $9,80 \%$ \\
\hline Internet & 13 & 0,2549 & $25,49 \%$ \\
\hline Pontualidade & 3 & 0,0588 & $5,88 \%$ \\
\hline Disponibilidade & 3 & 0,0588 & $5,88 \%$ \\
\hline Interesse & 4 & 0,0784 & $7,84 \%$ \\
\hline Dedicação & 2 & 0,0392 & $3,92 \%$ \\
\hline Equipamentos & 2 & 0,0392 & $3,92 \%$ \\
\hline Total & \multicolumn{3}{|l}{} \\
\hline
\end{tabular}

Fonte: Dados da Pesquisa (2020)

A execução de projetos a distância pressupõe, além da identificação das necessidades inerentes à esta modalidade, a compreensão das variáveis que compõem o seu sistema, esta que subsidia a busca por soluções eficientes (DAUDT, 2013). Tais pressupostos colocam outros desafios à tona, pois refletem as desigualdades educacionais cada vez mais acentuadas que se agravararam nesse período de pandemia, sendo preciso infraestrutura adequada e estratégias institucionais arquitetadas para atender às necessidades dos distintos perfis socioeconômicos de estudantes voluntários dos projetos.

Em relação ao interesse dos Coordenadores em manter o desenvolvimento dos projetos, 77,4\% pretenderam dar continuidade as atividades de forma presencial. Quando perguntados sobre a importância do projeto proposto, 51,6\% dos Coordenadores apontaram destaque no âmbito social, e outros 35,5\% indicaram relevância acadêmica, como demonstra o Gráfico 3. Tais resultados favorecem diversos questionamentos quanto à execução e elaboração dos projetos ofertados pelo PET, uma vez que as ações extensionistas possuem novas demandas sociais e um redirecionamento na sua atuação determinadas pelo contexto pandêmico. 
Gráfico 3: Relevância dos projetos realizados pelo PET

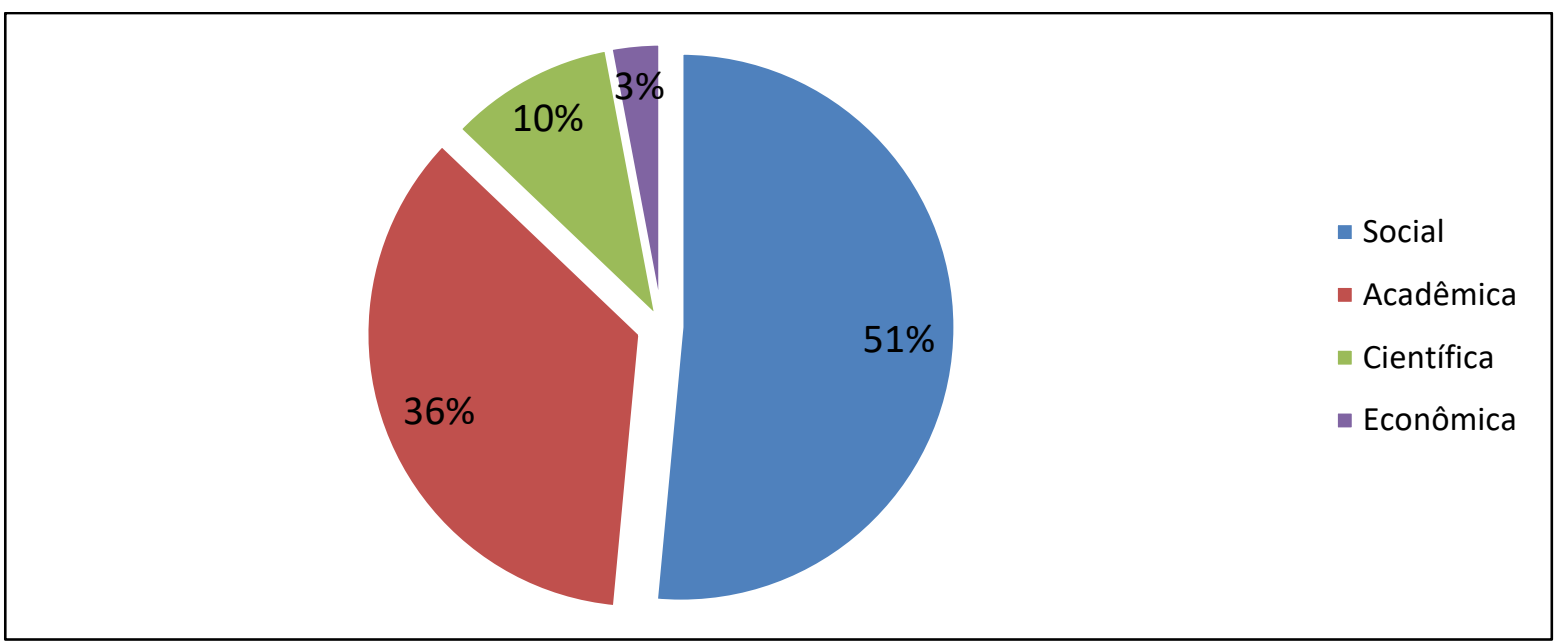

Fonte: Dados da pesquisa (2020)

Quando perguntados sobre a adaptação aos projetos, 41,9\% dos Coordenadores declararam que não houve necessidade, visto que 83,9\% estabeleceram canal de comunicação com os alunos. No entanto, 58,1\% constataram apropriado perante situação emergencial, mas somente $29 \%$ obtiveram sucesso após adaptação. O Gráfico 4 apresenta o quanto dos projetos de extensão conseguiram prosseguir após adaptação para serem desenvolvidos de forma online. Os dados declarados realçam a importância da construção de alianças entre tecnologias inerentes às práticas pedagógicas, diante da incerteza quanto à duração do surto viral e de como serão as necessidades pós-pandemia.

Gráfico 4: Desenvolvimento dos projetos após adaptação dos Coordenadores

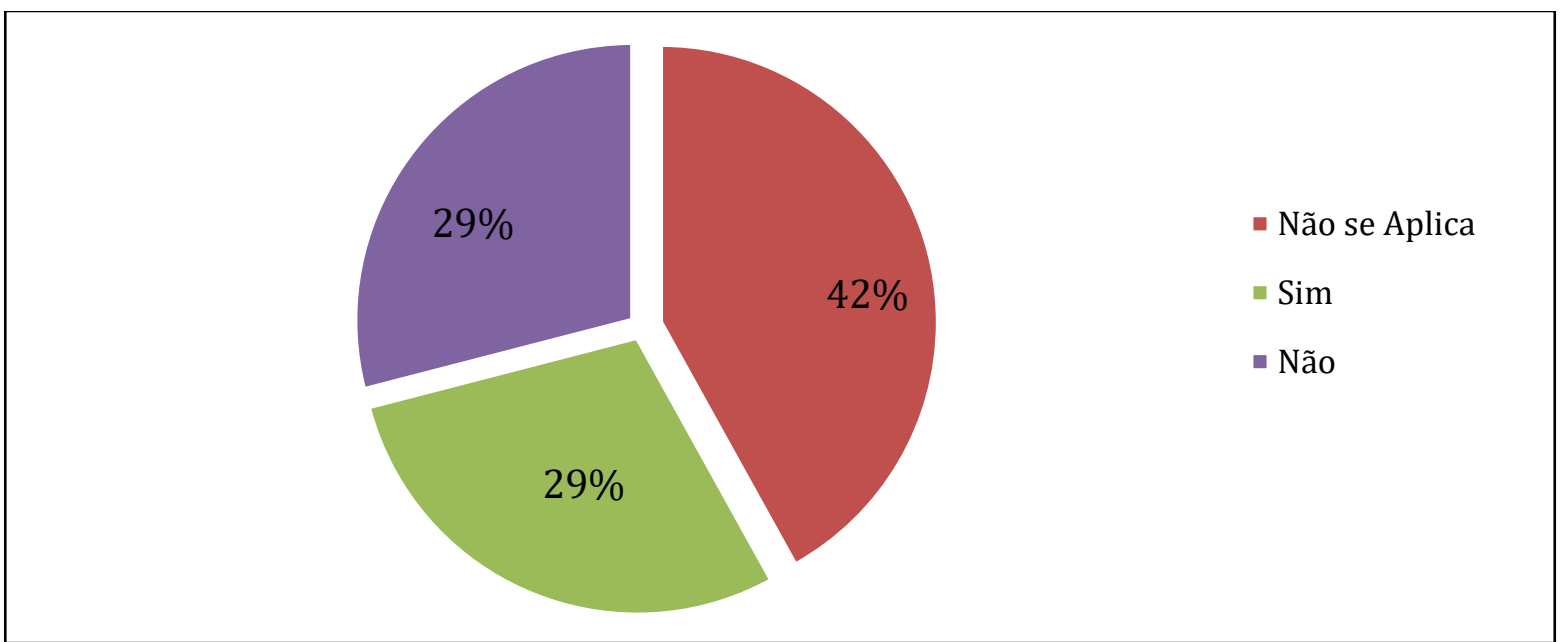

Fonte: Dados da pesquisa (2020)

O avanço tecnológico cria e disponibiliza, a todo momento, novas formas de interação entre as pessoas, o que obriga as universidades a frequentes atualizações nas suas estruturas. 
Diante disso, os resultados encontrados fornecem reflexões em relação a necessidade de propor modelos educacionais inovadores que facilitem a aprendizagem online e estimulem a convivência em rede, fatores que contribuem diretamente para diminuir a taxa de retenção e evasão. Implantar modelos capazes de conduzir os estudantes a articularem intensamente as relações, atualizando-se no modo de ver, estar e conviver em um espaço de aprendizagem diferente (DAUDT, 2013).

Quanto à divulgação dos resultados dos projetos, 74,2\% dos Coordenadores demonstraram interesse e 66,7\% dos Petianos informaram que há intenção por parte dos voluntários em publicar em eventos científicos ou acadêmicos. Desta forma, submeteu-se 17 trabalhos, em diferentes modalidades e eixos temáticos, ao $1^{\circ}$ Congresso Brasileiro Interdisciplinar em Ciência e Tecnologia. O objetivo deste evento é congregar profissionais, docentes, servidores e estudantes para consolidação e integração no cenário da educação superior brasileira, objetivo este que se alinha aos propósitos estabelecidos pelo PET Estratégias.

Coordenadores e Petianos relataram as principais habilidades que os projetos de extensão oportunizam aos discentes desenvolverem enquanto voluntários, como é apresentado na Tabela 2. Dentre as habilidades mais ditas pelos entrevistados estão a comunicação e escrita em destaque com 46,8\%, e o trabalho em equipe com $17,02 \%$ de frequência.

Tabela 2: Ocorrências das principais habilidades relatadas pelos Petianos e Coordenadores

\begin{tabular}{c|c|c|c}
\hline \multicolumn{4}{c}{ Habilidades no desenvolvimento dos projetos de extensão } \\
\hline Habilidades & $\begin{array}{c}\text { Frequência } \\
\text { Absoluta }\end{array}$ & $\begin{array}{c}\text { Frequência } \\
\text { Relativa }\end{array}$ & $\begin{array}{c}\text { Frequência } \\
\text { Relativa } \\
\text { Percentual }\end{array}$ \\
\hline $\begin{array}{c}\text { Trabalho em } \\
\text { Equipe }\end{array}$ & 8 & 0,1702 & $17,02 \%$ \\
\hline $\begin{array}{c}\text { Comunicação e } \\
\text { Escrita }\end{array}$ & 22 & 0,4680 & $46,80 \%$ \\
\hline Criatividade & 4 & 0,0851 & $8,51 \%$ \\
\hline Empatia & 6 & 0,1276 & $12,76 \%$ \\
\hline Objetividade & 7 & 0,1489 & $14,86 \%$ \\
\hline Total & & 47 & \\
\hline
\end{tabular}

Fonte: Dados da Pesquisa (2020)

Os resultados demonstram que a comunicação e a escrita se tornaram fundamentais na maioria dos projetos de extensão. Ademais, a comunicação é um processo que promove sinergia para alcançar os resultados almejados, e quando bem empregada auxilia na integração entre todos os colaboradores, permitindo transpor ideias predominantemente individuais para os grupais. A introdução de tecnologias voltadas à comunicação, provoca a criação de novas 
oportunidades de aprendizagem que possam se efetivar a qualquer hora, em qualquer lugar e de múltiplas maneiras. Toda atividade de aprendizagem envolve comunicação, que, por sua vez, necessita de ferramentas para se concretizar, o que reafirma a impossibilidade de concluir totalmente os projetos de extensão.

Em relação ao nível de satisfação, a maioria dos Coordenadores (32,3\%) manifestaram regular a execução remota dos projetos, outros $26 \%$ expressaram nível muito bom. Embora nenhum Petiano tenha indicado satisfação excelente, $66,7 \%$ apontaram nível de satisfação regular nesta pesquisa. Indaga-se diante dos resultados, que o desenvolvimento de projetos a distância exige competências específicas para o estabelecimento de metodologias eficientes que respondam às demandas neste momento, para que assim, tanto Petianos e Coordenadores quanto estudantes voluntários, adquiram experiências predominante excelentes ao atuarem como colaboradores do programa.

Na transição da modalidade presencial para a distância, os conceitos da presença física e virtual demandam uma atenção redobrada, e neste contexto de extensão universitária online, as formas de acesso e permanência dos alunos têm-se mostrado um grande desafio para o PET Estratégias. No entanto, a integração entre as ações voltadas ao ensino e aprendizagem a distância traz à tona a possibilidade de estabelecer redes que interliguem saberes diversos em favor da sociedade. O grupo PET em consonância com a realidade atual dos projetos, tornou público a chamada para propostas extensionistas ancoradas em conexões e pluralidades, adaptadas para serem desenvolvidas de forma remota, oportunizando o surgimento de uma nova cultura de aprendizagem, onde a virtualidade em projetos de extensão é vista como mais uma possibilidade para a universidade.

Os ambientes virtuais escolhidos para execução dos projetos de extensão, possibilitou o enriquecimento dos espaços de aprendizagem. As ferramentas tecnológicas como o Google Classroom, Google Drive e Youtube, ampliaram a interdisciplinaridade e a aprendizagem cooperativa entre os envolvidos, privilegiando a autonomia e o protagonismo na construção do conhecimento. Além disso, aspectos relacionados a interação, convivência e diminuição do sentimento de isolamento social foram impulsionados pelo uso de plataformas como o Google Meet, WhatsApp, Instagram e Facebook. O relacionamento de confiança efetivado na convivência entre Coordenadores, Petianos e voluntários é fundamental na constituição da segurança do estudante em relação aos projetos ofertados pelo PET Estratégias e à própria universidade. 


\section{CONSIDERAÇÕES FINAIS}

Nessa pesquisa, elencaram-se os empecilhos do PET Estratégias para garantia da manutenção e oferta dos projetos de extensão da UFVJM no semestre letivo 2020/1. Os resultados demonstraram que os projetos foram em sua maioria suspensos, tendo como principais razões: a indisponibilidade de internet por parte dos alunos, e a impossibilidade de acesso à universidade e aos equipamentos de pesquisa (ex: laboratório, instrumentos, ferramentas, entre outras) necessários para realização eficiente dos projetos de extensão.

Em geral, os dados que se referem às dificuldades para realização das atividades, indicam a necessidade de se elaborar estratégias que busquem mitigar as condições heterogêneas de acesso, para reduzir ao máximo o risco de ampliação das desigualdades educacionais, principalmente para os voluntários do programa que se encontram em estado de vulnerabilidade socioeconômica, e portanto, devem receber maior atenção da política educacional, em especial neste momento de crise.

No entanto, há um grande interesse tanto dos coordenadores de projetos, quanto dos Petianos na manutenção das atividades, onde a maioria aponta a necessidade de adaptações para tornar viável a execução, perante o cenário atual. Além disso, prosseguir com os projetos contribui para a indissociabilidade entre o ensino, pesquisa e extensão, operacionalizando a democratização do saber acadêmico e o retorno desse saber, uma vez que tríade reforça o papel solidário, social e cultural do estudante para com a sociedade. Cabe ainda enaltecer o PET Estratégias, por propiciar a interlocução entre os mais diversos campos do conhecimento e incentivar a publicação científica.

Embora o desenvolvimento remoto dos projetos possa contribuir para reduzir o impacto na formação dos universitários, é fundamental planejar estratégias eficazes à altura dos desafios que surgem nesta mudança. Estas estratégias só podem ser determinadas com um robusto conjunto de ações, que necessariamente precisarão contemplar novas e excepcionais demandas, ao fornecer apoio aos profissionais Coordenadores dos projetos e um acompanhamento mais próximo dos voluntários com maior propensão ao abandono ou evasão.

\section{AGRADECIMENTOS}

Ao Programa de Educação Tutorial Estratégias para Diminuir a Retenção e Evasão pelos benefícios. Aos Petianos e Coordenadores de projetos por colaborarem com os dados da pesquisa. 


\section{REFERÊNCIAS}

BRAGIATTO, Bruna Lopes; MATTA, Cristiane Maria Barra da. Adaptação acadêmica autoeficácia no contexto da pandemia COVID-19. 2020. Disonível em: $<$ https://maua.br/files/122020/adaptacao-academica-autoeficacia-contexto-pandemia-covid19-151501.pdf>. Acesso em: 01 mar. 2021.

CARVALHO, Cecilia Resende et al. O Programa de Educação Tutorial (PET) no contexto da crise econômica brasileira. Extensão em Foco, [S.1.], v. 1, n. 15, feb. 2018. ISSN 2358-7180. Disponível em: 〈https://revistas.ufpr.br/extensao/article/view/52730>. Acesso em: 04 ago. 2020.

CORDEIRO, Karolina Maria de Araújo. O Impacto da Pandemia na Educação: A Utilização da Tecnologia como Ferramenta de Ensino. 2020. Disponível em: <http://repositorio.idaam.edu.br/jspui/handle/prefix/1157>. Acesso em: 01 mar. 2021.

DAUDT, Sônia Isabel Dondonis; BEHAR, Patricia Alejandra. A gestão de cursos de graduação a distância e o fenômeno da evasão. Educação, v. 36, n. 3, p. 412-421, 2013. Disponível em: <https://revistaseletronicas.pucrs.br/index.php/faced/article/view/15543>. Acesso em: 25 fev. 2021.

DEARO, Patrícia Rossetti; NAKAYAMA, Jessica Tamy Oliveira; ROSSIT, Rosana Aparecida Salvador. Potencialidades e fragilidades do Programa de Educação Tutorial: percepções de acadêmicos. Caminho Aberto, p. 37-45, 2017. Disponível em: <https://periodicos.ifsc.edu.br/index.php/caminhoaberto/article/view/2071>. Acesso em: 23 ago. 2020.

FEITOSA, Raphael Alves; DIAS, Ana Maria Iório. Articulação entre ensino, pesquisa e extensão: Contribuições do programa de educação tutorial (PET) para a formação de graduandos em Biologia. Educação \& Formação, v. 4, n. 3, p. 169-190, 2019. Disponível em: <https://revistas.uece.br/index.php/redufor/article/view/819>. Acesso em: 10 set. 2020.

GARCIA, José Antonio Dias; CARVALHO, Maria das Graças de Souza; LIMA, Samuel José Fernandes de; ALVES, Laís Roncato de Carvalho; SILVA, Aline Guerrera Santos; OLIVEIRA, Felipe Santana; PEREIRA, Flávia Helena; SHMIDT, Fernanda Mateus Queiroz; MOTA, Kárita Santos; ALMEIDA, Dérica Karoly Evarista; FILHO, Cloves Gomes de Carvalho. Ensino professional e tecnológico na pandemia COVID-19: context politico e educacional. 2020. Disponível em: 〈http://dx.doi.org/10.33448/rsd-v9i12.10789>. Acesso em: 01 mar. 2021.

GUSSO, Hélder Lima, ARCHER, Aline Battisti., Luiz, Fernanda Bordignon., Sahão, Fernanda Torres., Luca, Gabriel Gomes de., Henklain, Marcelo Henrique Oliveira., Panosso, Mariana Gomide., Kienen, Nádia., Beltramello, Otávio., \& Gonçalves, Valquiria Maria. (2020). Ensino superior em tempos de pandemia: diretrizes à gestão universitária. Educação \& Sociedade, 41, e238957. Disponível em: <https://www.scielo.br/pdf/es/v41/1678-4626-es41-e238957.pdf>. Acesso em: 01 mar. 2021.

IBGE - Instituto Brasileiro de Geografia e Estatística (2018). Pesquisa Nacional por Amostra de Domicílios Contínua. Acesso à internet e à televisão e posse de telefone 
móvel celular para uso pessoal PNAD continua. 2018. Disponível em: <https://biblioteca.ibge.gov.br/index.php/biblioteca-catalogo?view=detalhes\&id=2101705> Acesso em: 01 mar. 2021.

IGUE, Érica Aparecida; BARIANI, Isabel Cristina Dib; MILANESI, Pedro Vitor Barnabé. Vivência acadêmica e expectativas de universitários ingressantes e concluintes. Psico-USF (Impr.). 2008, vol.13, n.2, pp.155-164. ISSN 1413-8271. Disponível em: $<$ https://www.scielo.br/scielo.php?pid=S141382712008000200003\&script=sci_abstract\&t $\underline{\operatorname{lng}=\mathrm{pt}>}$. Acesso em: 01 mar. 2021.

MINAYO, Maria Cecília de Souza. Pesquisa social: teoria, método e criatividade. 21. ed. Petrópolis: Vozes, 2002.

OCDE- Organisation de Cooperation et de Développement Économiques. A framework to guide an education response to the COVID-19 pandemic of 2020. 2020. Disponível em: <https://www.hm.ee/sites/default/files/framework_guide_v1_002_harward.pdf >. Acesso em: 01 de março de 2021.

PROGRAMA DE EDUCAÇÃO TUTORIAL PET ESTRATÉGIAS PARA DIMINUIR A RETENÇÃO E EVASÃO. Proposta. Disponível em: <https://sites.google.com/view/petestrategias/inicio?authuser $=0$ >. Acesso em: 25 set. 2020.

SCHNEIDER, Eduarda Maria; FUJII, Rosangela Araujo Xavier; CORAZZA, Maria Júlia. Pesquisas quali-quantitativas: contribuições para a pesquisa em ensino de ciências. Revista Pesquisa Qualitativa, v. 5, n. 9, p. 569-584, 2017. Disponível em: <https://editora.sepq.org.br/index.php/rpq/article/view/157>. Acesso em: 25 fev. 2021

SILVA, Sandro Pereira et al. Extensão universitária, economia solidária e geração de oportunidades no contexto da Covid-19: uma visão a partir de três experiências concretas no território brasileiro. Instituto de Pesquisa Econômica Aplicada (Ipea). 2020. Disponível em: 〈http://repositorio.ipea.gov.br/handle/11058/10189>. Acesso em: 10 set. 2020.

UNIVERSISIDADE FEDERAL DOS VALES DO JEQUITINHONHA E MUCURI. PET Estratégias oferece oportunidade para alunos de Diamantina. Disponível em: $<$ http://portal.ufvjm.edu.br/noticias/2020/pet-estrategias-oferece-oportunidade-para-alunosde-diamantina-1>. Acesso em: 01 mar. 2021.

Artigo recebido em: 12 de novembro de 2020.

Artigo aceito em: 03 de março de 2021.

Artigo publicado: 05 de abril de 2021. 